\title{
Photocatalytic Activities of Hydrothermally Synthesized $\mathrm{Zn}_{2} \mathrm{SnO}_{4}$
}

\author{
Myung-Jin Kim, Seong-Hun Park, ${ }^{\dagger}$ and Young-Duk Huh ${ }^{*}$ \\ Department of Chemistry, Dankook University, Institute of Nanosensor and Biotechnology, Gyeonggi-Do 448-701, Korea \\ *E-mail: ydhuh@dankook.ac.kr(Y.-D.Huh) \\ ${ }^{\dagger}$ Department of Chemistry, University of Seoul, Seoul 130-743, Korea \\ Received January 10, 2011, Accepted March 22, 2011
}

Key Words : $\mathrm{Zn}_{2} \mathrm{SnO}_{4}$, Hydrothermal synthesis, Photocatalytic activities

Zinc stannate $\left(\mathrm{Zn}_{2} \mathrm{SnO}_{4}\right)$ is a transparent conducting oxide with high electron mobility, high electrical conductivity and low visible absorption, and is used widely as gas sensors, electrode materials, and photoluminescence materials. ${ }^{1-3}$ $\mathrm{Zn}_{2} \mathrm{SnO}_{4}$ has also attracted considerable interest for its high photocatalytic activity. The decomposition reactions of benzene and water-soluble dyes using $\mathrm{Zn}_{2} \mathrm{SnO}_{4}$ as a photocatalyst were reported. ${ }^{4-7} \mathrm{Zn}_{2} \mathrm{SnO}_{4}$ is normally synthesized by solid state reactions with $\mathrm{ZnO}$ and $\mathrm{SnO}_{2}$ at high temperatures. ${ }^{8,9}$ The high temperature calcination of coprecipitated $\mathrm{Zn}$ and $\mathrm{Sn}$ hydroxides with the alkali from an aqueous solution were also used to prepare $\mathrm{Zn}_{2} \mathrm{SnO}_{4} \cdot{ }^{4,10}$ Recently, the hydrothermal synthesis of $\mathrm{Zn}_{2} \mathrm{SnO}_{4}$ was reported. ${ }^{11-13}$ Hydrothermal methods have advantages over the solid state reactions and high temperature calcinations methods, such as a lower reaction temperature and simpler method for producing nano-sized particles. Therefore, hydrothermal methods should be used to prepare $\mathrm{Zn}_{2} \mathrm{SnO}_{4}$ nanoparticles to improve the photocatalytic activity. However, relatively little is known regarding the relationship between the photocatalytic activity and synthetic conditions of hydrothermal methods of $\mathrm{Zn}_{2} \mathrm{SnO}_{4}$. This paper reports the photocatalytic activity of $\mathrm{Zn}_{2} \mathrm{SnO}_{4}$ nanoparticles prepared by a simple hydrothermal method from $\mathrm{Zn}\left(\mathrm{CH}_{3} \mathrm{COO}\right)_{2}$ and $\mathrm{SnCl}_{4}$ with different amounts of $\mathrm{NH}_{4} \mathrm{OH}$ to control the $\mathrm{pH}$ from 8 to 11 . The photocatalytic activity of $\mathrm{Zn}_{2} \mathrm{SnO}_{4}$ nanoparticles prepared by hydrothermal synthesis from $\mathrm{Zn}\left(\mathrm{CH}_{3} \mathrm{COO}\right)_{2}$ and $\mathrm{SnCl}_{4}$ with different types of hydroxylation agents at $\mathrm{pH} 9$ was also examined.

Figure 1 shows XRD patterns of the as-prepared samples obtained by hydrothermal methods from $\mathrm{Zn}\left(\mathrm{CH}_{3} \mathrm{COO}\right)_{2}$ and $\mathrm{SnCl}_{4}$ in the presence of different amounts of $\mathrm{NH}_{4} \mathrm{OH}$ to control the $\mathrm{pH}$ from 8 to 11. At $\mathrm{pH} 8$ and 9, the XRD patterns showed only a $\mathrm{Zn}_{2} \mathrm{SnO}_{4}$ phase. The products consisted of a single $\mathrm{Zn}_{2} \mathrm{SnO}_{4}$ crystals in the $\mathrm{Fd} 3 \mathrm{~m}$ cubic crystal system (JCPDS 24-1470, $a=0.8657 \mathrm{~nm}$ ). When the $\mathrm{pH}$ was increased to 10 , most of the products match the $\mathrm{Zn}_{2} \mathrm{SnO}_{4}$ phase. However, $\mathrm{ZnSn}(\mathrm{OH})_{6}$ coexisted with $\mathrm{Zn}_{2} \mathrm{SnO}_{4}$ as minor peaks in the XRD patterns. When the $\mathrm{pH}$ was increased further to 11, the product consisted of a single $P n 3 m$ cubic crystal system of $\mathrm{ZnSn}(\mathrm{OH})_{6}$ (JCPDS 20-1455, $a=0.7800$ $\mathrm{nm})$. Therefore, $\mathrm{Zn}_{2} \mathrm{SnO}_{4}$ is formed below the $\mathrm{pH} \mathrm{10}$, and $\mathrm{ZnSn}(\mathrm{OH})_{6}$ is formed above the $\mathrm{pH} 10$.

Figure 2 shows TEM and SEM images of the $\mathrm{Zn}_{2} \mathrm{SnO}_{4}$ and $\mathrm{ZnSn}(\mathrm{OH})_{6}$ products obtained at various $\mathrm{pH}$. At $\mathrm{pH} 8$ and 9, aggregated forms of $\mathrm{Zn}_{2} \mathrm{SnO}_{4}$ nanoparticles were observed, as shown in Figures 2(a) and 2(b). However, micronsized, cubic-shaped $\mathrm{ZnSn}(\mathrm{OH})_{6}$ products were observed at $\mathrm{pH}$ 11, as shown in Figure 2(d). This suggests that $\mathrm{ZnSn}(\mathrm{OH})_{6}$ has a characteristic cubic-shaped morphology. On the other hand, $\mathrm{Zn}_{2} \mathrm{SnO}_{4}$ nanoparticles do not have a unique morphology. The coexistence of $\mathrm{Zn}_{2} \mathrm{SnO}_{4}$ and $\mathrm{ZnSn}(\mathrm{OH})_{6}$ was observed at $\mathrm{pH} 10$. Figure 2(c) shows $\mathrm{Zn}_{2} \mathrm{SnO}_{4}$ nanoparticles attached to the outer surface of the micron-sized cubic $\mathrm{ZnSn}(\mathrm{OH})_{6}$ crystals. Figure 3 shows high-resolution TEM (HRTEM) image of the $\mathrm{Zn}_{2} \mathrm{SnO}_{4}$ nanoparticles obtained at $\mathrm{pH}$ 9. The size of the individual nanoparticle was approximately $10 \mathrm{~nm}$. The observed lattice spacing of $0.49 \mathrm{~nm}$ corresponded to the (111) plane of cubic $\mathrm{Zn}_{2} \mathrm{SnO}_{4}$ crystals. The fast Fourier transform (FFT) pattern corresponds to the lattice fringe, as shown in the inset of Figure 3.

To examine the photocatalytic activity of $\mathrm{Zn}_{2} \mathrm{SnO}_{4}$ and $\mathrm{ZnSn}(\mathrm{OH})_{6}$ products obtained by hydrothermal methods, Rh6G was chosen as the pollutant model molecule. The photodegradation of Rh6G under UV lamp irradiation after the addition of $\mathrm{Zn}_{2} \mathrm{SnO}_{4}$ and $\mathrm{ZnSn}(\mathrm{OH})_{6}$ as photocatalysts was evaluated. Figure 4(a) shows the temporal evolution of the UV-vis spectra of Rh6G in the absence of a catalyst. The absorption peaks of Rh6G decreased slightly with the irradiation time. The concentrations of Rh6G species were calculated simply from the maximum absorption intensities at $527 \mathrm{~nm}$ using the Beer-Lambert law. The photodegradation

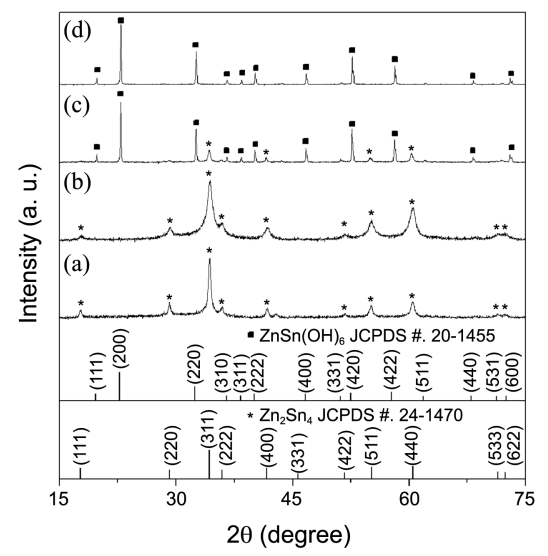

Figure 1. XRD patterns of the as-prepared samples obtained by hydrothermal methods from $\mathrm{Zn}\left(\mathrm{CH}_{3} \mathrm{COO}\right)_{2}$ and $\mathrm{SnCl}_{4}$ in the presence of $\mathrm{NH}_{4} \mathrm{OH}$ at $\mathrm{pH}$ (a) 8, (b) 9, (c) 10, and (d) 11 . 


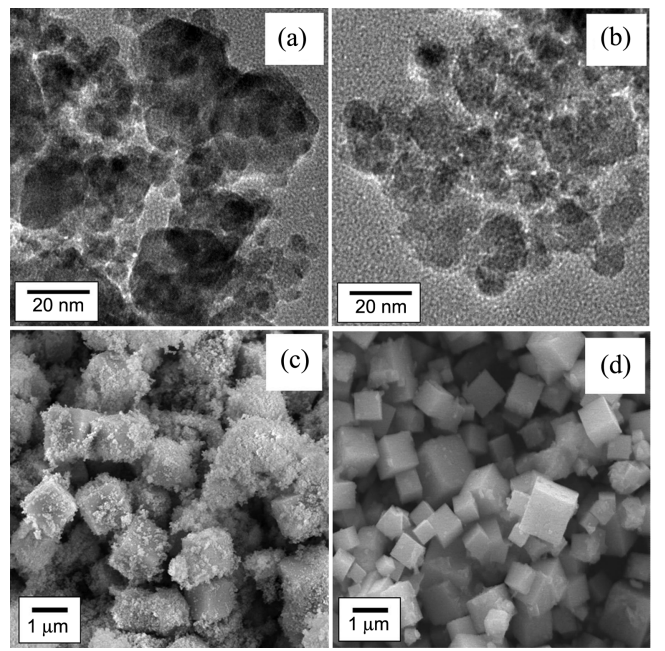

Figure 2. TEM and SEM images of the as-prepared samples obtained by hydrothermal methods from $\mathrm{Zn}\left(\mathrm{CH}_{3} \mathrm{COO}\right)_{2}$ and $\mathrm{SnCl}_{4}$ in the presence of $\mathrm{NH}_{4} \mathrm{OH}$ at $\mathrm{pH}$ (a) 8, (b) 9, (c) 10, and (d) 11 .

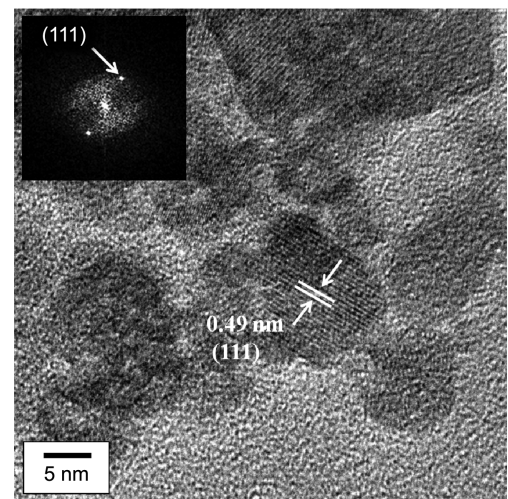

Figure 3. HRTEM image of the $\mathrm{Zn}_{2} \mathrm{SnO}_{4}$ product obtained by a hydrothermal method at $\mathrm{pH} 9$. The inset shows the FFT patterns of the $\mathrm{Zn}_{2} \mathrm{SnO}_{4}$ product.

efficiency was only $2.2 \%$ for 90 min, which demonstrated that the photodegradation of Rh6G was extremely low in the absence of a catalyst. Figures 4(b), 4(c), 4(d) and 4(e) show the temporal evolution of the UV-vis spectra of Rh6G in the presence of four $\mathrm{Zn}_{2} \mathrm{SnO}_{4}$ and $\mathrm{ZnSn}(\mathrm{OH})_{6}$ products prepared at different $\mathrm{pH}$ values. The absorption peaks of Rh6G decreased gradually at a given irradiation time in the presence of $\mathrm{Zn}_{2} \mathrm{SnO}_{4}$ and $\mathrm{ZnSn}(\mathrm{OH})_{6}$. The Rh6G solution was almost decolorized after irradiation for 90 min when $\mathrm{Zn}_{2} \mathrm{SnO}_{4}$ prepared at $\mathrm{pH} 9$ was used. This suggests that Rh6G was almost photodegradated within $90 \mathrm{~min}$. The samples prepared at $\mathrm{pH}$ $8,9,10$ and 11 have photodegradation efficiencies of $85.2 \%$, $90.5 \%, 70.5 \%$ and $28.1 \%$ for $90 \mathrm{~min}$, respectively. Therefore, the photocatalytic properties of $\mathrm{Zn}_{2} \mathrm{SnO}_{4}$ products were superior to those of the $\mathrm{ZnSn}(\mathrm{OH})_{6}$ products. The $\mathrm{Zn}_{2} \mathrm{SnO}_{4}$ products prepared at $\mathrm{pH} 9$ shows the highest photocatalytic property. $\mathrm{TiO}_{2}$ powder (Degussa, $\mathrm{P}-25$ ) was chosen as the well known reference photocatalyst to compare the photocatalytic activity of $\mathrm{Zn}_{2} \mathrm{SnO}_{4}$. Figure 4(f) shows the UV-vis spectral changes in $\mathrm{Rh} 6 \mathrm{G}$ in the presence of $\mathrm{TiO}_{2}$ powder. When $\mathrm{TiO}_{2}$ powder was used, $95.1 \%$ photodegradation of Rh6G was observed after 90 min.
Most of photodegradation reactions of dyes obey firstorder reaction kinetics. ${ }^{14,15}$ The reaction rate constant can be obtained simply from the integrated form of first-order reaction kinetics according to equation (1).

$$
\ln \left(\frac{C}{C_{0}}\right)=-k t
$$

where $C_{0}$ is the initial concentration, $C$ is the concentration of Rh6G after a set UV irradiation time. Figure 5 shows the first-order reaction kinetic plots of the photodegradation of Rh6G in the absence of a catalyst and in the presence of the as-prepared samples prepared at four different $\mathrm{pH}$ values. As shown in Figure 5, straight lines were observed. This suggests that the photodegradation of Rh6G obeys first-order reaction kinetics. The rate constant for the photodegradation of Rh6G in the absence of a catalyst and in the presence of $\mathrm{Zn}_{2} \mathrm{SnO}_{4}$ and $\mathrm{ZnSn}(\mathrm{OH})_{6}$ products prepared at $\mathrm{pH} 8,9,10$ and 11 were $2.0 \times 10^{-4}, 2.0 \times 10^{-2}, 2.5 \times 10^{-2}, 1.4 \times 10^{-2}$, and $3.8 \times 10^{-3} \mathrm{~min}^{-1}$, respectively. Therefore, the photocatalytic activity of $\mathrm{Zn}_{2} \mathrm{SnO}_{4}$ is better than that of $\mathrm{ZnSn}(\mathrm{OH})_{6}$. The BET surface areas of $\mathrm{Zn}_{2} \mathrm{SnO}_{4}$ and $\mathrm{ZnSn}(\mathrm{OH})_{6}$ prepared at $\mathrm{pH}$ of $8,9,10$ and 11 were $82.5,94.8,15.4$, and $13.5 \mathrm{~m}^{2} / \mathrm{g}$, respectively. The photocatalytic activity of $\mathrm{Zn}_{2} \mathrm{SnO}_{4}$ depends strongly on the BET surface areas of $\mathrm{Zn}_{2} \mathrm{SnO}_{4}$. The rate constant for the photodegradation of Rh6G in the presence of $\mathrm{TiO}_{2}$ powder was $3.1 \times 10^{-2} \mathrm{~min}^{-1}$. Based on the rate constant of photodegradation of Rh6G, the photocatalytic activity of $\mathrm{Zn}_{2} \mathrm{SnO}_{4}$ prepared at $\mathrm{pH} 9$ using $\mathrm{NH}_{4} \mathrm{OH}$ is approximately $81 \%$ that of the $\mathrm{TiO}_{2}$ powder. $\mathrm{ZnSn}(\mathrm{OH})_{6}$ with BET surface areas of $48 \mathrm{~m}^{2} / \mathrm{g}$ was used as a photocatalyst for the decomposition reactions of benzene. ${ }^{16}$ Even though overall photocatalytic activity of $\mathrm{Zn}_{2} \mathrm{SnO}_{4}$ is superior to that of $\mathrm{ZnSn}(\mathrm{OH})_{6}$ in this work, the photocatalytic activity of $\mathrm{ZnSn}(\mathrm{OH})_{6}$ prepared at $\mathrm{pH} 11$ was slightly better than that of $\mathrm{Zn}_{2} \mathrm{SnO}_{4}$ prepared at $\mathrm{pH} 9$ when rate constants are normalized to surface area. This suggest that $\mathrm{ZnSn}(\mathrm{OH})_{6}$ with larger BET surface area can be an excellent photocatalyst. We will plan to prepare the $\mathrm{ZnSn}(\mathrm{OH})_{6}$ with larger BET surface area to enhance the photocatalytic activitiy of $\mathrm{ZnSn}(\mathrm{OH})_{6}$ later.

$\mathrm{NaOH}, \mathrm{NH}_{4} \mathrm{OH}$, DMEDA, and TMEDA were used as a ligand and hydroxylation agent to examine the effect of the ligand on photocatalytic activity of $\mathrm{Zn}_{2} \mathrm{SnO}_{4}$ obtained using hydrothermal methods at $\mathrm{pH}$ 9. XRD patterns of four products matched the reported data for single $\mathrm{Zn}_{2} \mathrm{SnO}_{4}$ crystals (JCPDS 24-1470, $a=0.8657 \mathrm{~nm}$ ) without impurities. Figure 6(a), 6(b), 6(c) and 6(d) show the UV-vis spectral changes in $\mathrm{Rh} 6 \mathrm{G}$ in the presence of the four $\mathrm{Zn}_{2} \mathrm{SnO}_{4}$ products prepared using $\mathrm{NaOH}, \mathrm{NH}_{4} \mathrm{OH}$, DMEDA, and TMEDA, respectively. The photodegradation efficiencies of Rh6G in the presence of $\mathrm{Zn}_{2} \mathrm{SnO}_{4}$ prepared using $\mathrm{NaOH}$, $\mathrm{NH}_{4} \mathrm{OH}$, DMEDA, and TMEDA were were $74.4 \%, 90.5 \%$, $95.5 \%$, and $84.2 \%$ for $90 \mathrm{~min}$, respectively. The rate constant for the photodegradation of Rh6G in the presence of $\mathrm{Zn}_{2} \mathrm{SnO}_{4}$ prepared using $\mathrm{NaOH}, \mathrm{NH}_{4} \mathrm{OH}$, DMEDA, and TMEDA was $1.5 \times 10^{-2}, 2.5 \times 10^{-2}, 3.2 \times 10^{-2}$ and $2.0 \times 10^{-2}$ $\mathrm{min}^{-1}$, respectively. The BET surface areas of $\mathrm{Zn}_{2} \mathrm{SnO}_{4}$ 

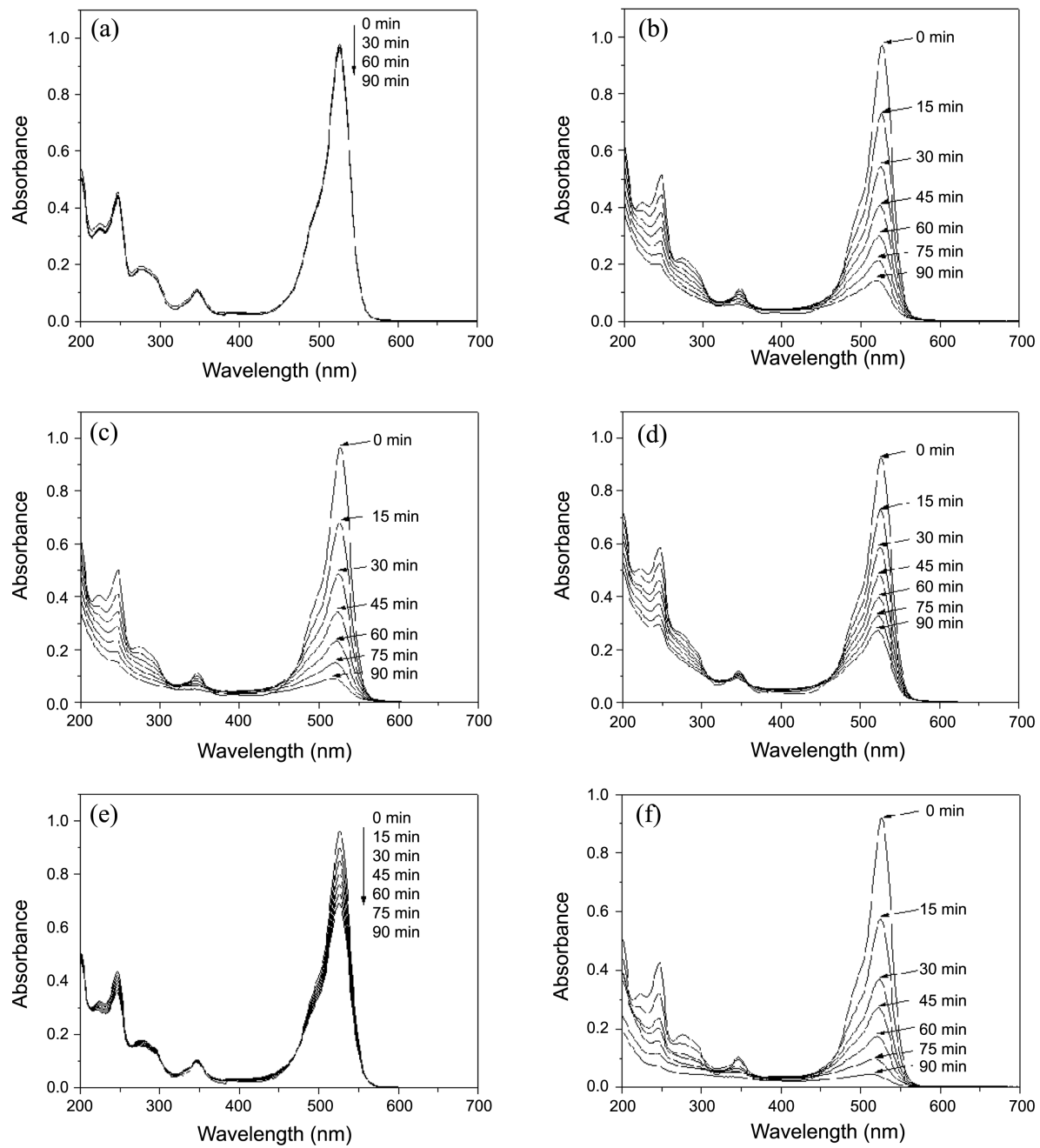

Figure 4. Absorption spectral changes in Rh6G during irradiation with UV light $(\lambda=254 \mathrm{~nm})(\mathrm{a})$ in the absence of a catalyst and in the presence of the $\mathrm{Zn}_{2} \mathrm{SnO}_{4}$ and $\mathrm{ZnSn}(\mathrm{OH})_{6}$ obtained at various $\mathrm{pH}$ (b) 8, (c) 9, (d) 10, (e) 11, and (f) in the presence of the $\mathrm{TiO}_{2}$ catalyst.

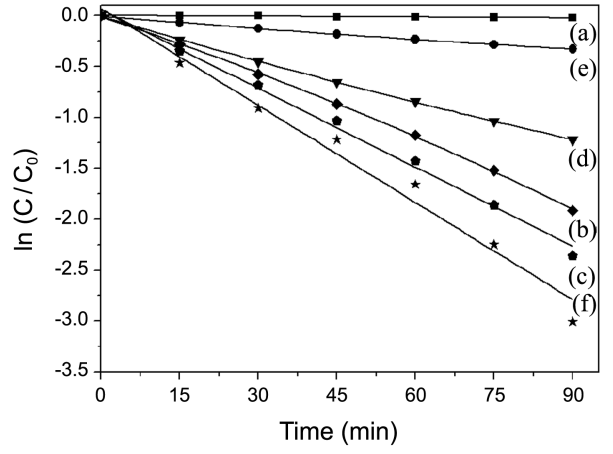

Figure 5. First-order reaction kinetic plots of the photodegradation of Rh6G (a) in the absence of a catalyst and in the presence of the $\mathrm{Zn}_{2} \mathrm{SnO}_{4}$ and $\mathrm{ZnSn}(\mathrm{OH})_{6}$ obtained at various $\mathrm{pH}$ (b) 8, (c) 9, (d) 10 , (e) 11 , and (f) in the presence of the $\mathrm{TiO}_{2}$ catalyst.

products prepared at $\mathrm{pH} 9$ using $\mathrm{NaOH}, \mathrm{NH}_{4} \mathrm{OH}$, DMEDA, and TMEDA were $57.2,94.8,86.6$, and $61.9 \mathrm{~m}^{2} / \mathrm{g}$, respectively. Therefore, the photocatalytic activities of $\mathrm{Zn}_{2} \mathrm{SnO}_{4}$ products prepared at $\mathrm{pH} 9$ using the different hydroxylation agents were in the following order: DMEDA $>\mathrm{NH}_{4} \mathrm{OH}>$ TMEDA $>\mathrm{NaOH}$. The photocatalytic activity of $\mathrm{Zn}_{2} \mathrm{SnO}_{4}$ prepared at $\mathrm{pH} 9$ using DMEDA was approximately $103 \%$ that of the well-known $\mathrm{TiO}_{2}$ photocatalyst.

In conclusion, $\mathrm{Zn}_{2} \mathrm{SnO}_{4}$ and $\mathrm{ZnSn}(\mathrm{OH})_{6}$ were synthesized using a hydrothermal reaction from $\mathrm{Zn}\left(\mathrm{CH}_{3} \mathrm{COO}\right)_{2}$ and $\mathrm{SnCl}_{4}$ with different amounts of $\mathrm{NH}_{4} \mathrm{OH}$. A single phase of $\mathrm{Zn}_{2} \mathrm{SnO}_{4}$ and $\mathrm{ZnSn}(\mathrm{OH})_{6}$ were formed at $\mathrm{pH} 8,9$, and $\mathrm{pH} 11$, respectively. At pH $10, \mathrm{Zn}_{2} \mathrm{SnO}_{4}$ and $\mathrm{ZnSn}(\mathrm{OH})_{6}$ coexisted. The photocatalytic activity of $\mathrm{Zn}_{2} \mathrm{SnO}_{4}$ prepared at $\mathrm{pH} 9$ was better than that of $\mathrm{ZnSn}(\mathrm{OH})_{6}$ prepared at $\mathrm{pH} 11$ by factor of 6.6. The photocatalytic activity of $\mathrm{Zn}_{2} \mathrm{SnO}_{4}$ nanoparticles prepared using the different hydroxylation agents were in the following order: DMEDA $>\mathrm{NH}_{4} \mathrm{OH}>$ TMEDA $>\mathrm{NaOH}$. The photocatalytic activity of $\mathrm{Zn}_{2} \mathrm{SnO}_{4}$ prepared at $\mathrm{pH} 9$ using DMEDA was almost equal to that of the well-known $\mathrm{TiO}_{2}$ photocatalyst.

\section{Experimental Section}

$\mathrm{Zn}\left(\mathrm{CH}_{3} \mathrm{COO}\right)_{2}$ (98\%, Aldrich), $\mathrm{SnCl}_{4}$ (98\%, Aldrich), $\mathrm{NaOH}$ (97\%, Aldrich), $\mathrm{NH}_{4} \mathrm{OH}$ (28\%, Aldrich), $N, N$-dimethyl ethylenediamnie (DMEDA, 95\%, Aldrich), $N, N, N^{\prime}, N^{\prime}$-tetramethyl ethylenediamnie (TMEDA, 99\%, TCI), Rhodamine 6G (Rh6G, $99 \%$, Aldrich), and $\mathrm{TiO}_{2}$ powder (Degussa, $\mathrm{P}-25$ ) were used 

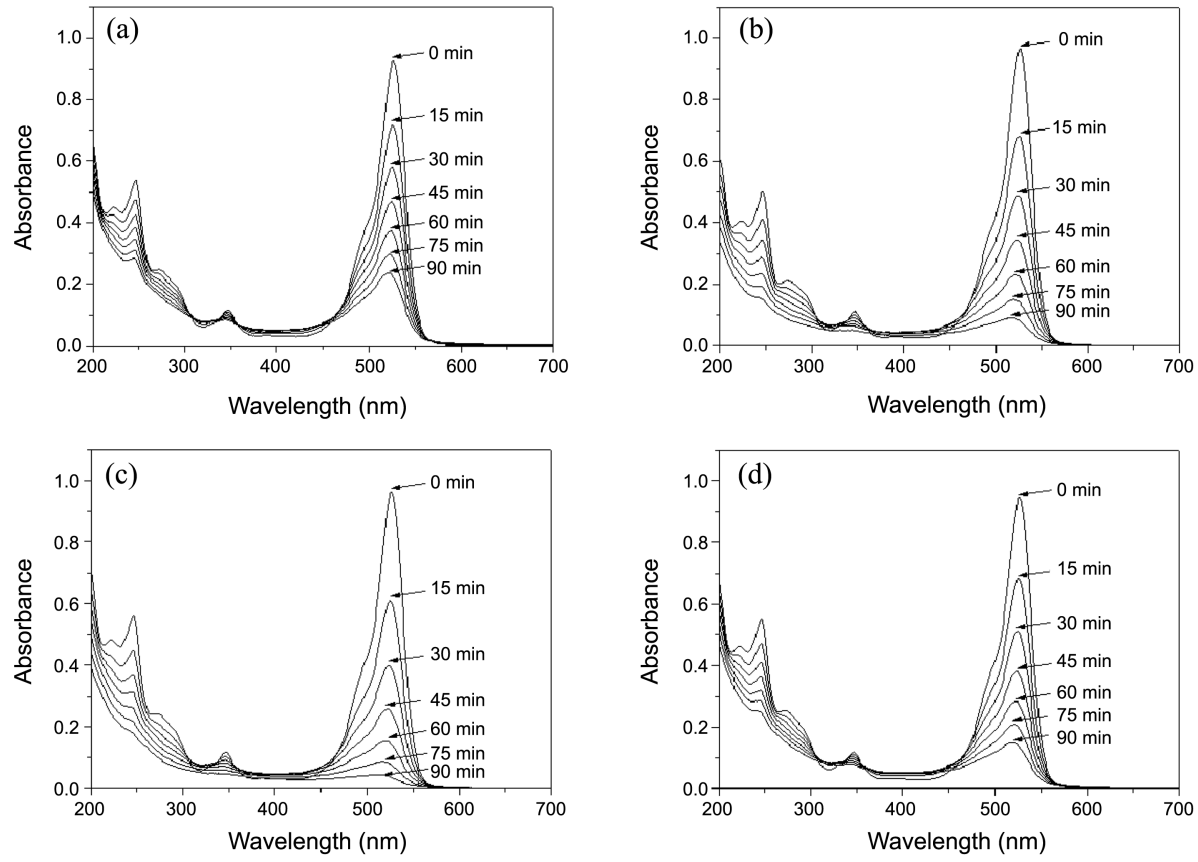

Figure 6. Absorption spectral changes in Rh6G during irradiation with UV light $(\lambda=254 \mathrm{~nm})$ in the presence of four $\mathrm{Zn}_{2} \mathrm{SnO}_{4}$ products prepared at pH 9 using (a) $\mathrm{NaOH}$, (b) $\mathrm{NH}_{4} \mathrm{OH}$, (c) DMEDA, and (d) TMEDA as a hydroxylation agent, respectively.

as received. In a typical experiment, $20 \mathrm{~mL}$ of a $0.10 \mathrm{M}$ $\mathrm{Zn}\left(\mathrm{CH}_{3} \mathrm{COO}\right)_{2}$ solution was added to $20 \mathrm{~mL}$ of a $0.05 \mathrm{M}$ $\mathrm{SnCl}_{4}$ solution. Different amounts of a $\mathrm{NH}_{4} \mathrm{OH}$ solution was added to the mixed solution to obtain the various $\mathrm{pH}$ values (pH 8, 9, 10, and 11). A $60 \mathrm{~mL}$ sample of the final solution was transferred to a $100 \mathrm{~mL}$ Teflon-lined autoclave and heated to $140{ }^{\circ} \mathrm{C}$ for $16 \mathrm{~h}$. The product was filtered, washed several times with ethanol and water, and dried at $80{ }^{\circ} \mathrm{C}$ for $12 \mathrm{~h}$.

The photocatalytic activity of the $\mathrm{Zn}_{2} \mathrm{SnO}_{4}$ and $\mathrm{ZnSn}(\mathrm{OH})_{6}$ samples was evaluated by the photodegradation of Rh6G under a $12 \mathrm{~W}$ UV lamp $(\lambda=254 \mathrm{~nm})$. In a typical procedure, $10 \mathrm{mg} \mathrm{Zn}_{2} \mathrm{SnO}_{4}$ (or $\mathrm{ZnSn}(\mathrm{OH})_{6}$ ) powder was added to 100 $\mathrm{mL}$ of $1.04 \times 10^{-5} \mathrm{M}$ Rh6G aqueous solutions in a $100 \mathrm{~mL}$ round bottom flask. The suspensions were then irradiated under a UV lamp at a $3 \mathrm{~cm}$ separation distance in dark condition. Every 15 minutes during the photodegradation process, $3 \mathrm{~mL}$ of the Rh6G solution was sampled and separated by centrifugation. The concentrations of the supernatants were monitored using a UV-vis spectrophotometer. To compare the photocatalytic activitiy of $\mathrm{TiO}_{2}$ with that of $\mathrm{Zn}_{2} \mathrm{SnO}_{4}, 10 \mathrm{mg}$ of $\mathrm{TiO}_{2}$ was used with the other conditions kept the same as those used for the photodegradation of Rh6G by adding $\mathrm{Zn}_{2} \mathrm{SnO}_{4}$.

The structures of the $\mathrm{Zn}_{2} \mathrm{SnO}_{4}$ and $\mathrm{ZnSn}(\mathrm{OH})_{6}$ products were characterized by powder X-ray diffraction (XRD, PANalytical, X'pert-pro MPD) using $\mathrm{Cu} \mathrm{K} \alpha$ radiation. The morphology of the products was observed by scanning electron microscopy (SEM, Hitachi S-4300) and transmission electron microscopy (TEM, JEOL JEM-3010). The BrunauerEmmett-Teller (BET) surface areas of the sample were calculated from the $\mathrm{N}_{2}$ adsorption/desorption isotherms determined at liquid nitrogen temperature using an automatic analyzer (Micrometric, Tristar 3020). Prior to adsorption, the samples were outgassed for $8 \mathrm{~h}$ under a vacuum at $120^{\circ} \mathrm{C}$.

Acknowledgments. This study was supported by Basic Science Research Program through National Research Foundation of Korea funded by the Ministry of Education, Science and Technology (2010-0007492).

\section{References}

1. Yamada, Y.; Seno, Y.; Masuoka, Y.; Yamashita, K. Sens. Actuators $B$ 1998, 49, 248.

2. Tan, B.; Toman, E.; Li, Y.; Wu, Y. J. Am. Chem. Soc. 2007, 129, 4162.

3. Wang, J. X.; Xie, S. S.; Yuan, H. J.; Yan, X. Q.; Liu, D. F.; Gao, Y.; Zhou, Z. P.; Song, L.; Liu, L. F.; Zhao, X. W.; Dou, X. Y.; Zhou, W. Y.; Wang, G. Solid State Commun. 2004, 131, 435.

4. Cun, W.; Xinming, W.; Jincai, Z.; Bixian, M.; Guoying, S.; Ping'an, P.; Jiamo, F. J. Mater. Sci. 2002, 37, 2989.

5. Foletto, E. L.; Jahn, S. L.; Moreira, R. F. P. M. J. Appl. Electrochem. 2010, 40,59

6. Lou, X.; Jia, X.; Xu, J.; Liu, S.; Gao, Q. Mat. Sci. Eng. A 2006, 432, 221.

7. Fu, X.; Wang, X.; Long J.; Ding, Z.; Yan, T. Zhang, G.; Zhang, Z.; Lin, H.; Fu, X. J. Solid State Chem. 2009, 182, 517.

8. Jie, J.; Wang, G.; Han, X.; Fang, J.; Yu, Q.; Liao, Y.; Xu, B.; Wang, Q.; Hou, J. G. J. Phys. Chem. B 2004, 108, 8249.

9. Chen, H.; Wang, J.; Yu, H.; Yang, H.; Xie, S.; Li, J. J. Phys. Chem. $B$ 2005, 109, 2573.

10. Wang, S.; Yang, Z.; Lu, M.; Zhou, Y.; Zhou, G.; Qiu, Z.; Wang, S.; Zhang, H.; Zhang, A. Mater. Lett. 2007, 61, 3005.

11. Zhu, H.; Yang, D.; Yu, G.; Zhang, H.; Jin, D.; Yao, K. J. Phys. Chem. B 2006, 110, 7631.

12. Alpuche-Aviles, M. A.; Wu, Y. J. Am. Chem. Soc. 2009, 131, 3216.

13. Zeng, J.; Xin, M. D.; Li, K. W.; Wang, H.; Yan, H.; Zhang. W. J. J. Phys. Chem. C 2008, 112, 4159.

14. Lin, J.; Lin, J.; Zhu, Y. Inorg. Chem. 2007, 46, 8378.

15. Kim, M. J.; Huh, Y. D. Mater. Res. Bull. 2010, 45, 1921.

16. Fu, X.; Wang, X.; Ding, Z.; Leung, D. Y. C.; Zhang, Z.; Long, J.; Zhang, W.; Li, Z.; Fu, X. Appl. Catal. B 2009, 91, 67. 